must forget the bad old imperial system and concentrate on learning drugs prescribed metrically. Iron for the past 30 years has been traditionally prescribed as ferrous sulphate (or gluconate) $1,3,5$, or 10 gr. t.i.d., and now we write $60,100,300$, or $600 \mathrm{mg}$. t.i.d. I have recently been prescribing ferrous sulphate $1 \mathrm{~g}$. night and morning. This brings me to my first point that when we adopt the metric system dosage we should wherever possible have doses of 1 g., $500 \mathrm{mg}$., $250 \mathrm{mg}$., and possibly $200 \mathrm{mg}$. and $100 \mathrm{mg}$. and the same proportions for microgrammes.

My second point concerns the recent letter which the Royal College of Nursing has sent to members of the tutor's section which tries to clarify the practice of drugs being ordered either in mg. or in decimal points of a gramme, and the following recommendations which have been approved by the Joint Formulary Committee of the British Medical Association and the Pharmaceutical Society:

(1) Quantities of solids less than 1 gramme should be given in milligrammes-e.g., 500 mg. not $0.5 \mathrm{~g}$.

(2) A zero should be written in front of the decimal point when there is no other figure-e.g., $0.5 \mathrm{ml}$. not $.5 \mathrm{ml}$.

(3) "Gramme" should be abbreviated to " G" written in a Block capital and not to "g." This will avoid any possibility of confusion with the abbreviation " $\mathrm{gr}$ " grain.

(4) Only weights of less than 0.1 milligramme should be expressed in terms of microgrammes.

In (1) less than a gramme is given in mg.e.g., $500 \mathrm{mg}$. is correct, ,but in (4) only weights less than $0.1 \mathrm{mg}$. are written in microgrammes-e.g., 500 microgrammes should be written $0.5 \mathrm{mg}$. This inconsistency is avoided by omitting decimal points, except for more than $1 \mathrm{~g}$.- e.g., $2.5 \mathrm{~g}$. Let us prescribe cyanocobalamin in doses of 250,500 microgrammes, or $1 \mathrm{mg}$. Let us write 500 milligrammes of tolbutamide t.i.d. and not $0.5 \mathrm{~g}$.

Many nurses are often poor mathematicians and need the simplest system. Manufacturers have helped already by supplying drugs in quantities of $1 \mathrm{~g}$., $500 \mathrm{mg}$., or $250 \mathrm{mg}$. With microgrammes the doses go down-e.g., L-thyroxine sodium 100 or 50 microgrammes.

Liquid measures present problems. The traditional teaspoonful is the basis of measurement, and it was with mixed feelings that I read in the "Recommendations for Labelling Liquid Medicines for Children when the Dose is Prescribed in the Metric System" "that the domestic teaspoon most commonly used holds about $5.0 \mathrm{ml}$., although smaller teaspoons holding about $3.5 \mathrm{ml}$. are also in general use." The forward-looking parent will probably insist on his child being born with the correct $5 \mathrm{ml}$. " metric teaspoon" in his mouth. If so there will be no need for the following recommendations for labelling, intended to assist pharmacists in dealing with this problem during the period before standardization of this dose-volume can be achieved:

(1) If $5 \mathrm{ml} ., 4 \mathrm{ml} ., 1 \mathrm{drachm}$ or 60 minims is prescribed as the dose-volume. Label "One teaspoonful. ..." (2) If $3.5 \mathrm{ml}$. is prescribed as the dose-volume. Label "One small teaspoonful. ..." (3) If $2.5 \mathrm{ml}$., $2 \mathrm{ml}$., $\frac{1}{2}$ drachm or 30 minims is prescribed as the dose-volume. Label "Half a teaspoonful. ..." (4) If $1 \mathrm{ml}$. or 15 minims is prescribed as the dose-volume. Label " $\mathrm{A}$ quarter teaspoonful. . . ." Approximations like this should be condemned at birth.

I have avoided $\mu$, the abbreviation for microgrammes. Doctors' writing and most people's Greek make this symbol less desirable than decimal points.

I ask you, therefore, if the Joint Committee could reconsider their recommendations before final instructions are given.- I am, etc.,

$$
\begin{aligned}
& \text { Hospital of St. Cross, } \\
& \text { Rugby. }
\end{aligned}
$$$$
\text { R. E. SMITH. }
$$
Rugby.

\section{Dental Anaesthesia}

SIR,-Between two million and three million patients a year in this country undergo general anaesthesia in the dental chairmore than the grand total for all other procedures of surgery. It is common knowledge that the methods in general use in dentistry are relics of Victorian practice and, by modern standards, anything but satisfactory.

There are now available methods of general anaesthesia that would revolutionize the patient's approach to dental treatment; the ordeal in a visit to the dentist would cease to exist. These methods have been extensively tested in dentistry, possibly by now in as many as a million patients, and their inherent safety is beyond question. But before they could be widely practised there would have to be intensive postgraduate training, for which existing facilities are wholly inadequate.

I suggest that every hospital group in the country should have a first-class dental clinic, fully equipped for all forms of routine dental treatment and all forms of anaesthesia, with first-class salaried dentists in attendance, and served by the hospital's anaesthetics department, if necessary with augmented staff. The clinic should be equipped not only with a dental chair but also with an operating couch. There should be recovery cubicles and a short-stay day-ward, so that some of the more extensive operations could be carried out in out-patients instead of admitting the patient to hospital.

Such clinics would be of great value: for handling the difficult anaesthetics case, referred from outside; for teaching the very large number of " occasional " anaesthetistsdoctors, dentists, and perhaps others-who are called on to do this work; for training our junior anaesthetists, so that we would no longer be turning out Fellows of the Faculty of Anaesthetists almost totally ignorant on the subject of dental anaesthetics ; for providing, up and down the country, abundant opportunities for research; and for setting standards of treatment, set-up, and lay-out to be followed by every dentist in the locality. The clinic would be a centre for postgraduate education in dentistry as well as anaesthetics. Perhaps ultimately all dentistry, like all other branches of surgery, might come to be done in hospital clinics.

There would be no shortage of patients in such clinics with the treatment being carried out under the modern methods of anaesthesia I have referred to.-I am, etc.,

$$
\text { London S.E.1. }
$$

$$
\text { J. G. Bourne. }
$$

\section{Aetiology of Abruptio Placentae}

SIR,-We welcome Dr. D. B. Paintin's summary of his observations concerning hypertension and abruptio placentae $(8$
February, p. 374). He finds it " difficult not to conclude that pre-existing hypertension predisposes to accidental haemorrhage." Even so, the incidence of hypertension in his series of abruptio placentae was increased by factors of only 1.6 for affected primigravidae and 3.4 for affected multigravidae. This is in broad agreement with our conclusions that "pre-eclampsia or essential hypertension may be important contributory factors in a limited number of cases."

Appreciating the possible bias resulting from selective hospital booking, which incidentally may affect Dr. Paintin's argument in either direction, we considered the relationship of abruptio placentae and preeclampsia from both aspects. Thus the incidence of pre-eclampsia in cases of abruptio was marginally higher than in the hospital population. The incidence of abruptio in 1,175 patients with pre-eclampsia was $1.6 \%$, or 1.5 times the overall incidence of abruptio, but it is still a very low figure and again supports our conclusion.

The only particular point over which we are at variance concerns the relationship of hypertension to blood loss, which Dr. Paintin claims does not occur in other circumstances. P. L. Mollison ${ }^{2}$ and others note the occurrence of transient hypertension following moderate haemorrhage from various causes, particularly in young adults. Our own observations on patients suffering post-partum haemorrhage and on those with bleeding from placenta praevia confirm these findings.-We are, etc.,

\section{Department of Obstetrics

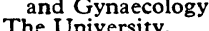

BRyan M. HibBard. ElIZABETH D. HibBaRd.

\section{Thiazide-induced Neonatal Haemolysis ?}

SIR,-There has been only limited support for the concept that thiazide diuretics administered for toxaemia of pregnancy may injure the foetus. Pritchard and Walley ${ }^{1}$ considered that severe metabolic derangement might have caused foetal death in a pregnant woman with severe hypokalaemia and metabolic alkalosis following prolonged ingestion of chlorothiazide. Watt and Philipp $^{2}$ had previously cited as a warning five instances of intrauterine death over a period of three months in women with toxaemia who were receiving diuretics of the chlorothiazide type, but the significance of these findings was questioned by Sears ${ }^{3}$ and by Assali. ${ }^{4}$

Recently, Garnet published experimental evidence showing that chlorothiazide was readily transferred transplacentally from mother to foetus ${ }^{5}$; these results were in contrast to the earlier experimental findings."

The object of this communication is to record two cases of Heinz-body haemolysis in the newborn infants of mothers who received thiazide derivatives in pregnancy, and to reopen the question as to whether such compounds may not under certain circumstances cause foetal or neonatal damage.

Case 1.-This male infant was first seen on 13 December 1960 at the age of 24 hours, with a history of progressive purpura since normal delivery at full term. The child weighed $3.5 \mathrm{~kg}$., and a generalized purpuric rash was the only 
abnormality noted on examination. The haemoglobin value was $12.6 \mathrm{~g} . / 100 \mathrm{ml}$, with marked anisocytosis and many nucleated erythrocytes, spherocytes, and aberrant forms in a smear of peripheral blood. Of the erythrocytes approximately $40 \%$ were reticulocytes, and approximately $80 \%$ contained Heinz bodies.

The total serum bilirubin content was $5.3 \mathrm{mg}$./ $100 \mathrm{ml}$. and the conjugated serum bilirubin content $0.4 \mathrm{mg} . / 100 \mathrm{ml}$. The mother's blood group was $\mathrm{O}, \mathrm{Rh}$ negative and the infant's blood group $\mathrm{O}, \mathrm{Rh}$ positive. The direct Coombs test was negative. The glucose-6-phosphate dehydrogenase (G6PD) activity by the method of Zinkham was 260 units $/ 100 \mathrm{ml}$. of erythrocytes.

After transfusion of $100 \mathrm{ml}$. of blood the infant's condition improved rapidly. On 23 December the child was free of jaundice and purpura, the haemoglobin level was $23 \mathrm{~g} . / 100$ ml., the erythrocytes were of normal appearance, and thrombocytes were present in normal numbers. The child has progressed well until the present time, with haemoglobin levels and thrombocyte counts within the normal range.

Both parents are of Anglo-Saxon racial ex traction. Over the last three weeks of pregnancy the mother had suffered from urinary symptoms and some oedema. For 15 days before delivery she had received sulphamethizole, $0.5 \mathrm{~g}$. every four hours, and chlorothiazide, $0.5 \mathrm{~g}$. daily.

Case 2. - This female infant was first seen on 29 July 1963 at the age of 4 days, with a history of slowly increasing jaundice from the age of 24 hours. The infant was believed to be three weeks premature, but the birth weight was $3.6 \mathrm{~kg}$. Gross jaundice was the only abnormality on physical examination. The total serum bilirubin content was $16.5 \mathrm{mg} . / 100 \mathrm{ml}$., and the conjugated serum bilirubin content less than $0.5 \mathrm{mg}$./ $100 \mathrm{ml}$. The haemoglobin level was $19.0 \mathrm{~g} . / 100$ ml., reticulocytes comprised about $3 \%$ of the erythrocytes, and Heinz bodies were present in approximately $20 \%$ of the erythrocytes. No spherocytes were detected, and the erythrocytes were mainly macrocytic and normochromic.

The mother's blood group was A, Rh positive and the infant's blood group $\mathrm{A}, \mathrm{Rh}$ negative. The direct Coombs test was negative. No immune antibodies were detected in the mother's serum against a large panel of erythrocytes. The G6PD activity was 166 units per $100 \mathrm{ml}$. of erythrocytes.

An exchange transfusion was done on the day after admission, after the total serum bilirubin had increased to $24 \mathrm{mg}$. $/ 100 \mathrm{ml}$. The jaundice subsequently faded slowly, and the haemoglobin value on 10 August was $12.3 \mathrm{~g} . / 100 \mathrm{ml}$., with no abnormality in a smear of peripheral blood and no Heinz bodies. The infant has progressed well since that time.

The child's father is of Italian and the mother forthern European racial extraction. The methaemoglobin reduction test ${ }^{7}$ was normal in both parents.

For 14 days before delivery the mother had received bendroflumethiazide, $5 \mathrm{mg}$. daily. Three to four months earlier she had taken phenmetrazine, 50-100 mg. daily for a short period. At delivery the infant received an intramuscular in;ection of $1 \mathrm{mg}$. of menadiol sodium diphosphate. Otherwise there is no history of recent exposure of either mother or infant to any aromatic chemical.

The association between administration of thiazide and development of Heinz-body haemolysis in these two patients may well be incidental. Denial of exposure to an unidentified haemolytic compound during the perinatal period is virtually impossible. Furthermore, sulphamethizole could have caused both haemolysis and thrombocytopenia in Case 1, and menadiol sodium diphosphate in a dose of $1 \mathrm{mg}$. might conceivably have contributed to the production of Heinz bodies in the patient in Case 2.

However, there does seem good reason to suspect a causal relation between maternal ingestion of thiazides and the haematological manifestations in these two patients. The heterocyclic sulphonamide structure of these compounds would appear compatible with conversion in vivo to aromatic derivatives which act as redox catalysts. Chlorothiazide administration has also been known to cause thrombocytopenia, ${ }^{8}$ which was probably responsible for the presenting sign of purpura in the patient in Case 1. Synergism between chlorothiazide and sulphamethizcle may well have accounted for the various haematological abnormalities in this first patient.

In recent observations on placental transfer of maternally ingested chlorothiazide quantitative analyses of plasma chlorothiazide in both maternal and cord-blood specimens were performed on 19 patients. $^{5}$ In $15 \mathrm{ex}-$ periments the maternal and foetal plasma levels were comparable, and in two the drug was identified in the maternal but not in the foetal blood. In the remaining two instances the drug could be identified in neither the maternal nor the foetal blood. These results suggest ready placental transfer of chlorothiazide, with the conversion in about $10 \%$ of pregnant women to a metabolic derivative which is not measurable as chlorothiazide. It seems reasonable to suggest that this unidentified derivative might produce haemolytic manifestations in a small proportion of cases of exposure to thiazide derivatives.

Apart from conversion to compounds which catalyse the oxidative destruction of haemoglobin and formation of Heinz bodies, thiazides could interfere with erythrocytic metabolism in other ways. Chlorothiazide appears to be intermediate in pharmacodynamic characteristics between carbonic anhydrase inhibitors and the organomercurial diuretic agents which inhibit sulphydryl enzymes. ${ }^{10}$ Inhibition of erythrocytic carbonic anhydrase would be particularly significant in the newborn infant, with a relative deficiency of this enzyme. ${ }^{11}$ Moreover, any effect on sulphydryl enzymes should profoundly influence the pathways of carbohydrate metabolism, which maintain the integrity of the red blood cell.

It is noteworthy that erythrocytic G6PD deficiency was found in neither infant. The histories of these patients thus provide some evidence that thiazide derivatives given prenatally may be haemotoxic to the normal newborn infant. This report will perhaps stimulate further interest in the possibility that neonatal damage may result from the present wide use of thiazide derivatives in obstetric practice.

We are grateful to Dr. Kathleen Winning for permission to publish the history of the patient in Case 1, and to Dr. V. A. Lovric for haematological studies.

-We are, etc.,

J. D. HARLEY.

HELEN ROBIN.

S. E. J. ROBERTSON.

Children's Medical Research Foundation

Royal Alexandra Hospital for Children,

REFERENCES

1 Pritchard, J. A., and Walley, P. J., Amer. F. Obstet. Gynec., 1961, 81, 1241.
Watt, J. D.; and Philipp, E. E., Brit. med. F., 1ears, R. T., ibid., 1960, 2, 148

4 Assali, N. S., J.'Amer. med. Ass., 1960, 174, Garnet, J. D., Obstet. and Gynec., 1963, 21, 123. - Zarnham, W., Obstet. and Gynec., 1963, 21, 123 Brewer, G. J.. Tarlov, A. R., and Alving, A. S.,
Bull. Wld Hilth Org., 1960, 22, 633. Ball, P. Y. F. Amer. med. Ass., 1960, 173, 663. Arch. intern. Med., 1958, 102, 1005

11 Stevenson, S. S., f. clin. Invest., 1943. 22. 403.
Vertebro-basilar Ischaemia

SIR,-I found Dr. Denis Williams's article on "Vertebro-basilar Ischaemia" (11 January, p. 84) most interesting. With reference to his statement, "... transient and reversible disturbances of cerebral and brainstem function-' little strokes'-are attributed to reduction in the speed of blood flow," I should like to call your attention to the following case observed in our neurological department some months ago.

A 51-year-old female patient complained of dizziness and fainting attacks whenever she turned her head briskly to the right side. We confirmed this by making her turn the head rapidly to the right, when she had a serious attack of vertigo and symptoms of collapse. $X$-ray examination of the cervical vertebral column showed that she suffered from pronounced spondylo-arthrosis, especially on the right side, where the intervertebral foramina seemed markedly narrowed. Vertebral arteriography enabled us to observe the slight constriction of the right vertebral artery whenever the patient moved her head slowly to the right. Quite understandably, therefore, a rapid and vigorous rotation of the neck might produce a profound narrowing of the artery, followed by vertigo and fainting attacks. After the patient had been given a collar made of light plastic the attacks stopped and she was able to lead a normal life.

-I am, etc.,

Neurological Department,

István Hospital, Budapest.

\section{T. LEHOCZKY.}

\section{Circulation of Cerebrospinal Fluid}

SIR,-Your leader (11 January, p. 72) ends by stating that evidence for absorption of the cerebrospinal fluid by the villi is less strong than that for its secretion by the choroid plexus, and that we cannot be certain that the villi are the only site of reabsorption. To testify to the practical importance of that site of absorption, may I quote a case of primary osteogenic sarcoma of the parasagittal area in a man aged 54 with raised pressure (partial destruction of the dorsum sellae, papilloedema, C.S.F. pressure of $315 \mathrm{~mm}$. water). ${ }^{1} \quad$ The diagnosis was confirmed by necropsy. No other reason for the rise in intracranial pressure was found. Other systems showed no malignancy, apart from secondaries in two ribs. No thrombosis of the sagittal sinus was found. Obviously involvement of the pacchionian granulations in the infiltrating growth and blockage to their reabsorption of the C.S.F. must have been the reason for the increase in intracranial pressure.-I am, etc.,

Newcastle, Staffs.

G. STEINER

REFBRENCE

1 Steiner, G., Brit. F. Radiol., 1949, 22, 235

\section{Sterile Syringe Service}

SIR,-The Minister of Health was reported in the B.M.F. of 7 December 1963 (p. 1477) as having stated that hospitals giving a laboratory service to general practitioners were in a position to provide sterile syringes for the taking of specimens free of charge. Attention was drawn to this statement by the Chairman of the G.M.S.C. in the report of the business of this committee (Supplement, 4 January, p. 3). 